\title{
The effect of schema therapy on emotion regulation, happiness, and procrastination in health center employees
}

\author{
Zeinab Hajikhaniyan ${ }^{1}$, Ali Nazeri Astaneh ${ }^{2,}{ }^{*}$, Gita Sadighi ${ }^{3}$ and Reza Koushkestani ${ }^{3}$ \\ 1 School of Psychology and Educational Sciences, South Branch, Islamic Azad University, Tehran, Iran. \\ ${ }^{2}$ Psychosis Research Center, the University of Social Welfare and Rehabilitation Sciences, Tehran, Iran. \\ ${ }^{3}$ Department of Psychiatry, the University of Social Welfare and Rehabilitation Sciences, Tehran, Iran.
}

Publication history: Received on 16 December 2019; revised on 14 January 2020; accepted on 16 January 2020

Article DOI: https://doi.org/10.30574/wjarr.2020.5.1.0107

\begin{abstract}
Schema therapy has been used in the treatment of various disorders, including depression, anxiety, personality disorders, and couples' incompatibility and has suggested promising outcomes. Therefore, the present study aimed to investigate the effects of schema therapy on emotion regulation, happiness, and procrastination among the staff of healthcare centers. This was a quasi-experimental study with a pretest-posttest and a control group design. The experimental groups received eleven 90-minute (once a week) schema therapy sessions, while the control group received no intervention. The statistical population consisted of the staff of comprehensive health centers in the east of Tehran City, Iran. In total, 40 samples were selected through systematic sampling method. The subjects were randomly divided into the test and control groups (20 samples per group). Considering the experimental nature of the study and eliminating the effect of pretest, the study groups were compared using the Analysis of Covariance (ANCOVA). In addition, Multivariate Analysis of Covariance (MANCOVA) and Analysis of Variance (ANOVA) were applied for testing the primary and secondary hypotheses, respectively. The obtained data were analyzed applying statistics like mean and standard deviation, as well as Multivariate Analysis of Variance (MANCOVA) in SPSS. There were significant differences between the two experimental and control groups in terms of emotion regulation $(\mathrm{P}<0.000)$ and happiness $(\mathrm{P}<0.003)$. However, there was no significant difference between the two groups in procrastination $(\mathrm{P}<0.689)$. According to the obtained data, conducting schema therapy has improved emotion regulation and happiness in the experimental group compared to the controls. However, the intervention only slightly improved procrastination in the experimental group members and such increase was not statically significant.
\end{abstract}

Keywords: Scheme therapy; Emotion regulation; Happiness; Procrastination

\section{Introduction}

Schema therapy, developed by Jeffrey E. Young, is a modern and integrated approach. It is mainly based on the development of the concepts and methods of standard cognitive-behavioral therapy. It is believed that schema therapy is a valuable and comprehensive model, consisting of the integration of the principles of cognitive-behavioral therapy, Gestalt, attachment theory, object-relation theory, constructivism theory, and psychoanalysis [Young, Klosko, \& Weishaar, 2003]. The fundamental concept of this approach is "initial maladaptive schemas" [Sempertegui, Karreman, Arntz, \& Bekker, 2013]. Schema therapy has been used in the treatment of a variety of disorders, including depression, anxiety, narcissistic personality disorder, borderline personality disorder, obsessive-compulsive personality disorder, and in couples' incompatibility and has suggested promising outcomes [Mitragotri, Kost, Kellogg, Warner, \& Elstrom, 2012]. Emotion regulation refers to a process by which individuals modulate their emotions in a conscious or nonconscious manner to appropriately respond to environmental demands [Tortella-Feliu, Balle, \& Sesé, 2010]. Emotion regulation is considered as an essential issue in mental health [Garnefski \& Kraaij, 2006]. Emotion regulation and its

\footnotetext{
${ }^{*}$ Corresponding author

E-mail address: alinazeri_76@yahoo.com
} 
relation to biopsychological health is an important research area [Connelly \& Denney, 2007]. Longitudinal studies have also highlighted that emotion regulation skills could predict mental health status [Berking et al., 2008]. Prior research suggested that emotion regulation problems are prevalent among a wide range of mental disorders [Gross \& Muñoz, 1995]. Otto et al. argued that success and happiness result from emotion regulation and recognized emotion reappraisal beneficial in reducing the effects of negative emotions [Otto, Misra, Prasad, \& McRae, 2014]. According to previous research studies, happier people benefit from a better biopsychological health status, live longer, and gain more occupational and social success [Scalmani et al., 2006]. Happiness reduces stress perception and enhances working ability [Hillis et al., 2004]. Procrastination is defined as suspending or delaying to perform a necessary task and delegating it until the deadline [Lay, 1986]. Experimental evidence suggests a correlation between procrastination and numerous mental health issues, academic performance matters, and social problems [Sirois, 2004]. A critical aspect that should be considered in organizations' human resources is developing constructive and satisfying interpersonal relationships. Improving early maladaptive schemas could affect such matters. To our knowledge, there is no study available regarding the effectiveness of schema therapy on emotion regulation, happiness, and procrastination among working staff. Therefore, the present study aimed to investigate the effects of schema therapy on the above-mentioned components among the staff of comprehensive healthcare centers.

\section{Participants and methods}

This was a quasi-experimental study with a pretest-posttest and a control group design. The experimental groups received eleven 90-minute (once a week) schema therapy sessions, while the control group received no intervention. The statistical population consisted of the staff of comprehensive healthcare centers in the east of Tehran City, Iran. In total, 40 samples were selected through systematic sampling method. The subjects were randomly divided into the test and control groups (20 samples per group). Considering the experimental nature of the study and eliminating the effect of pretest, the study groups were compared using the Analysis of Covariance (ANCOVA). In addition, Multivariate Analysis of Covariance (MANCOVA) and Analysis of Variance (ANOVA) were applied for testing the primary and secondary hypotheses, respectively. The obtained data were analyzed applying descriptive statistics like mean and standard deviation, as well as inferential statistics, including Multivariate Analysis of Variance (MANCOVA), in SPSS.

\section{Study instruments:}

- Emotion Regulation Questionnaire (ERQ): This scale has been developed by Gross and John in 2003 [Gullone \& Taffe, 2012]. It includes 10 items and 2 subscales of reappraisal (6 questions) and repression (4 questions). The reappraisal subscale examines individuals 'willingness to modulate emotions through cognitive change, while the repression subscale examines individuals' tendency to control their emotions. This questionnaire is rated on a 7-point Likerttype scale (1: strongly agree to 7: strongly disagree). The sum of all scores on each subscale represents the individual score on that subscale. The lowest and the highest values for the reappraisal and repression subscales are 6 and 42 , as well as 4 and 28, respectively. According to Gross and John, the scale's internal consistency scores for reappraisal and repression were found to be 0.79 and 0.73 , respectively. Additionally, its test-retest reliability (within 3 months) was calculated as 0.69 for both components of the questionnaire. In the present study, Cronbach's alpha coefficients were equal to 0.83 for reappraisal and 0.79 for repression, and 0.86 for the whole test.

- The Oxford Happiness Survey: This 9-item questionnaire was developed by Michael Argyle and Peter Hills at Oxford University [Gullone \& Taffe, 2012]. It evaluates the cognitive and emotional elements of happiness. The scale includes 29 items rated on a six-point Likert-type scale, with the 5 following subscales: life Satisfaction, self-esteem, subjective well-being, satisfaction, and positive mood. In the present study, Cronbach's alpha coefficient for the whole test was calculated as 0.88 .

- General Procrastination Scale (GPS): This tool consists of 20 items. Responses across items are summed to obtain a single score, and according to the instructions of GPS, the scale is one-factor only scale, with Cronbach alpha of 0,82 [Gullone \& Taffe, 2012] and retest reliability of 0,80 (Ferrari, 1989). The obtained scores are rated on a Likerttype scale. There are 5 possible options to respond to the items in this questionnaire ranging from one to five. The higher the achieved score, the greater the procrastination level. Negative items are scored reversely. In the present study, Cronbach's alpha coefficient for the whole test was calculated as 0.79 .

The contents of the 11 sessions of schema therapy provided to the test group are presented in the below table. 
Table 1 The schema therapy sessions outline

\begin{tabular}{ll}
\hline Sessions & Purpose \\
\hline 1 & $\begin{array}{l}\text { Conducting the pretest, reviewing the treatment structure, } \\
\text { purposes, and logic, explaining group rules }\end{array}$ \\
2 & Introducing schemas and how they are developed \\
3,4 & Educating and implementing cognitive techniques \\
$5,6,7$ & Educating and implementing experimental (emotional) \\
& techniques \\
$8,9,10$ & Educating and implementing the techniques of \\
& breaking behavioral patterns \\
11 & Performing posttest \\
\hline
\end{tabular}

\section{Results}

The current study was conducted on 40 samples, who were randomly divided into the test and control groups $(20$ samples per group). All 20 participants in the experimental group completed the study.

Table 2 presents the demographic data of the samples. The age of the study samples ranged from 26 to 51 years, and their mean age was 37.92 years. Moreover, the majority of the study participants were married (80\%) females (77.5\%). In addition, most of the subjects benefited from higher education levels (BA \& MA=, 71\%).

Table 2 The demographic data of the study participants

\begin{tabular}{|c|c|c|c|c|c|}
\hline Variable & & Value & $\begin{array}{l}\text { Frequency } \\
\text { (No.) }\end{array}$ & Percentage (\%) & The cumulative frequency (\%) \\
\hline \multirow[t]{6}{*}{ Age } & Mean & 37.92 & & & \\
\hline & Median & 37.5 & & & \\
\hline & Mode & 36 & & & \\
\hline & SD & 6.47 & & & \\
\hline & Min. & 26 & & & \\
\hline & Max. & 51 & & & \\
\hline \multirow[t]{3}{*}{ Gender } & Male & & 9 & 22.5 & \\
\hline & Female & & 31 & 77.5 & \\
\hline & Total & & 40 & 100 & \\
\hline \multirow{3}{*}{$\begin{array}{l}\text { Marital } \\
\text { status }\end{array}$} & Single & & 8 & 20 & \\
\hline & Married & & 32 & 80 & \\
\hline & Total & & 40 & 100 & \\
\hline \multirow{5}{*}{$\begin{array}{l}\text { Educational } \\
\text { status }\end{array}$} & \multicolumn{2}{|c|}{ High-school diploma } & 5 & 12.5 & 12.5 \\
\hline & \multicolumn{2}{|c|}{ Associate degree } & 7 & 17.5 & 30 \\
\hline & \multicolumn{2}{|c|}{ Bachelor's degree } & 14 & 35 & 65 \\
\hline & \multicolumn{2}{|c|}{ Master's degree } & 14 & 36 & 100 \\
\hline & \multicolumn{2}{|c|}{ Total } & 40 & 100 & - \\
\hline
\end{tabular}

According to Table 3, although the mean difference between the two groups in the happiness variable was low, the mean scores in the experimental group were slightly higher, indicating that the application of the schema therapy in the experimental group increased the happiness in the subjects. Moreover, concerning emotion regulation, the mean scores of the experimental group were higher, indicating that the application of the schema therapy improved their emotion regulation. Eventually, the mean scores of the experimental group were slightly higher in terms of procrastination, indicating that schema therapy caused a slight increase in procrastination in the experimental group. 
Table 3 Posttest statistics of the experimental and control groups

\begin{tabular}{llll}
\hline Test & Group & Mean & SD \\
\hline \multirow{3}{*}{ Emotion Regulation } & Experimental & 48.60 & 2.87 \\
& Control & 36.75 & 1.88 \\
& Total & 42.67 & 6.46 \\
& Experimental & 24.26 & 1.24 \\
Happiness & Control & 22.24 & 1.07 \\
& Total & 24.62 & 1.15 \\
Procrastination & Experimental & 60.95 & 2.79 \\
& Control & 60.55 & 2.01 \\
& Total & 60.75 & 2.41 \\
\hline
\end{tabular}

As per Table 4, the Levene's test results were not significant for any of the variables. Therefore, the Analysis of Variance (ANOVA) could have been used to test the achieved data.

Furthermore, Multivariate Analysis of Covariance (MANCOVA) was used to investigate the therapeutic effect of schema therapy on the studied employees' emotion regulation, happiness, and procrastination. By controlling pretest scores and comparing posttest scores, the two experimental and control groups were compared.

Table 4 Levene's test results for the equality of variances

\begin{tabular}{lllll}
\hline Variable & F & df1 & df2 & P \\
\hline Emotion Regulation & 2.161 & 1 & 38 & 0.052 \\
Happiness & 0.511 & 1 & 38 & 0.479 \\
Procrastination & 2.784 & 1 & 38 & 0.055 \\
\hline
\end{tabular}

According to Table 5, there was a significant difference between the two groups in terms of happiness, emotion regulation, and procrastination. Therefore, the experimental intervention was effective in the variables mentioned above.

The multivariate test difference was statistically significant; thus, the one-way Analysis of Covariance (ANCOVA) was applied to examine group differences regarding the dependent variable. The ANCOVA results are presented in Table 6.

Table 5 MANCOVA results regarding the effect of schema therapy on the studied employees' emotion regulation, happiness, and procrastination

\begin{tabular}{lllllll}
\hline Statistic & Measure & F & df & df error & P & Eta sq. \\
\hline Pillai's trace & 0.899 & 97.909 & 3 & 33 & 0.000 & 0.899 \\
$\begin{array}{l}\text { Wilk's } \\
\text { lambda }\end{array}$ & 0.101 & 97.909 & 3 & 33 & 0.000 & 0.899 \\
$\begin{array}{l}\text { Hotelling's } \\
\text { Trace }\end{array}$ & 8.901 & 97.909 & 3 & 33 & 0.000 & 0.899 \\
$\begin{array}{l}\text { Roy's } \\
\text { Largest Root }\end{array}$ & 8.901 & 97.909 & 3 & 33 & 0.000 & 0.899 \\
\hline
\end{tabular}


There were significant differences between the two experimental and control groups in terms of happiness (P<0.003) and emotion regulation $(\mathrm{P}<0.000)$. However, there was no significant difference between the two groups in procrastination $(\mathrm{P}<0.689)$.

Table 6 One-way ANCOVA results regarding the effect of schema therapy on the studied employees' emotion regulation, happiness, and procrastination.

\begin{tabular}{lllllll}
\hline Variable & Sum of Squares & df & Mean Squares & F & P & Eta sq. \\
\hline Emotion Regulation & 1441.974 & 1 & 1441.947 & 300.015 & 0.000 & 0.896 \\
Happiness & 3770.971 & 1 & 3770.971 & 10.098 & 0.003 & 0.224 \\
Procrastinations & 0.824 & 1 & 0.824 & 0.162 & 0.689 & 0.005 \\
\hline
\end{tabular}

\section{Discussion}

The MANCOVA results revealed that the difference between the two groups was significant in terms of emotion regulation and happiness components $(\mathrm{P}<0.0001)$. Therefore, schema therapy has increased happiness in the experimental group. Diener argued that happiness is associated with three components, as follows: the cognitive component, i.e., thinking and processing that leads to one's optimism; the emotional component which causes positive and happy mood; and the social component that reflects one's tendency toward communicating with others and the resulted joy of effective communication [Diener, 2005]. Therefore, understanding the schemas and treating them can be an essential step in developing emotion regulation skills and increasing happiness accordingly. This finding was consistent with other studies [Elahi, Sepahmansour, Golshani, \& Emamipour, 2016; Moradi Siah Afshadi, Amiri, \& Molavi, 2017], [Renner et al., 2018), [Bamelis, Renner, Heidkamp, \& Arntz, 2011] [Bamelis et al., 2011], (Bach \& Farrell, 2018].

Furthermore, the mean scores of the experimental group were higher than those of the controls in emotion regulation. In other words, schema therapy increased emotion regulation in the experimental subjects. Employing emotion regulation strategies could increase positive emotions, decrease negative emotions, and consequently improve the sense of happiness [Kalokerinos, Greenaway, \& Denson, 2015]. Otto et al. also attributed success and happiness to emotion regulation and recognized emotion reappraisal as influential in reducing the effects of negative emotion. Thus, recognizing schemas and reducing their associated impairments could be an important step in developing emotion regulation skills and improving happiness [Otto et al., 2014].

The literature highlights that emotion regulation predicts positive compatibility. Moreover, the capability to effectively manage emotions could impact biopsychological and interpersonal happiness [Gross, 2002]. These study findings were consistent with some of the previous research findings [Abbasi, Pirani, \& Salehi, 2017], [Calvete, Orue, \& Hankin, 2013].

In the case of procrastination, there was a negligible difference between the mean scores of two test and control groups. The slightly higher mean scores of the experimental group indicated that schema therapy slightly improved procrastination in them. It can be concluded that the schema therapy did not affect the procrastination and the observed difference could only be due to a random basis. Possibly, many contextual factors, including perfectionism and the lack of planning skills might affect procrastination in individuals. Moreover, encouraging procrastinating people to engage in group therapy, which is focused on changing behaviors is much harder than other situations.

A study limitation included strict sample selection to a specific region of Tehran. In addition, controlling the effect of some demographic factors, such as intelligence, economic status, etc. was disregarded in the present research; such issues might affect the generalizability of the obtained data. The experimental nature of the study which targets assessing causal relations might be another limitation; thus, further study is suggested to investigate the study variables through more comprehensive research methods.

The achieved study results could be beneficial in improving employee's emotion regulation strategies and job satisfaction, leading to their increased working efficiency and effective communication skills. 


\section{Conclusion}

According to the obtained data, conducting schema therapy has improved emotion regulation and happiness in the experimental group compared to the controls. However, the intervention only had slightly improved procrastination in the experimental group members, and such an increase was not statically significant.

\section{Compliance with ethical standards}

\section{Acknowledgments}

The authors would like to acknowledge the contributions of all the study participants in this work.

\section{Disclosure of conflict of interest}

The authors declared no conflicts of interest.

\section{Statement of ethical approval}

All procedures performed in the study involving human participants were by the ethical standards of the institutional and national research committee and with the 1964 Helsinki declaration and its later amendments or comparable ethical standards.

\section{Statement of informed consent}

Informed consent was obtained from all individual participants included in the study.

\section{References}

[1] Young JE, Klosko JS and Weishaar ME. (2003). Schema therapy: A practitioner's guide: Guilford Press.

[2] Sempertegui GA, Karreman A, Arntz A and Bekker MH. (2013). Schema therapy for borderline personality disorder: A comprehensive review of its empirical foundations, effectiveness and implementation possibilities. Clinical psychology review, 33(3), 426-447.

[3] Mitragotri SS, Kost J, Kellogg SC, Warner NF and Elstrom TA. (2012). Method and apparatus for enhancement of transdermal transport: Google Patents.

[4] Tortella-Feliu M, Balle M and Sesé A. (2010). Relationships between negative affectivity, emotion regulation, anxiety, and depressive symptoms in adolescents as examined through structural equation modeling. Journal of Anxiety Disorders, 24(7), 686-693.

[5] Garnefski N and Kraaij V. (2006). Relationships between cognitive emotion regulation strategies and depressive symptoms: A comparative study of five specific samples. Personality and Individual differences, 40(8), 16591669.

[6] Connelly M and Denney DR. (2007). Regulation of emotions during experimental stress in alexithymia. Journal of psychosomatic research, 62(6), 649-656.

[7] Berking M, Wupperman P, Reichardt A, Pejic T, Dippel A and Znoj H. (2008). Emotion-regulation skills as a treatment target in psychotherapy. Behaviour research and therapy, 46(11), 1230-1237.

[8] Gross JJ. (2002). Emotion regulation: Affective, cognitive, and social consequences. Psychophysiology, 39(3), 281291.

[9] Otto B, Misra S, Prasad A and McRae K. (2014). Functional overlap of top-down emotion regulation and generation: An fMRI study identifying common neural substrates between cognitive reappraisal and cognitively generated emotions. Cognitive, Affective, \& Behavioral Neuroscience, 14(3), 923-938.

[10] Scalmani G, Frisch MJ, Mennucci B, Tomasi J, Cammi R and Barone V. (2006). Geometries and properties of excited states in the gas phase and in solution: Theory and application of a time-dependent density functional theory polarizable continuum model. The Journal of chemical physics, 124(9), 094107. 
[11] Hillis AE, Work M, Barker PB, Jacobs MA, Breese EL and Maurer K. (2004). Re-examining the brain regions crucial for orchestrating speech articulation. Brain, 127(7), 1479-1487.

[12] Lay CH. (1986). At last, my research article on procrastination. Journal of research in personality, 20(4), 474-495.

[13] Sirois FM. (2004). Procrastination and intentions to perform health behaviors: The role of self-efficacy and the consideration of future consequences. Personality and Individual differences, 37(1), 115-128.

[14] Gullone E and Taffe J. (2012). The Emotion Regulation Questionnaire for Children and Adolescents (ERQ-CA): A psychometric evaluation. Psychological assessment, 24(2), 409.

[15] Ferrari JR. (1989). Reliability of academic and dispositional measures of procrastination. Psychological Reports, 64(3_suppl), 1057-1058.

[16] Diener E. (2005). Frequently asked questions about subjective well-being (Happiness and Life satisfaction). Aprimer for reporters and newcomers.

[17] Elahi E, Sepahmansour M, Golshani F and Emamipour S. (2016). Comparing the Effect of Schema-Based Education and Social Problem Solving Training on Social Competence and Expressions of Identity in Adolescents. Mediterranean Journal of Social Sciences, 7(5 S1), 64.

[18] Renner F, DeRubeis R, Arntz A, Peeters F, Lobbestael J and Huibers MJ. (2018). Exploring mechanisms of change in schema therapy for chronic depression. Journal of behavior therapy and experimental psychiatry, 58, 97-105.

[19] Bamelis LL, Renner F, Heidkamp D and Arntz A. (2011). Extended schema mode conceptualizations for specific personality disorders: An empirical study. Journal of Personality Disorders, 25(1), 41-58.

[20] Bach B and Farrell JM. (2018). Schemas and modes in borderline personality disorder: The mistrustful, shameful, angry, impulsive, and unhappy child. Psychiatry research, 259, 323-329.

[21] Kalokerinos EK, Greenaway KH and Denson TF. (2015). Reappraisal but not suppression downregulates the experience of positive and negative emotion. Emotion, 15(3), 271.

[22] Otto B, Misra S, Prasad A and McRae K. (2014). Functional overlap of top-down emotion regulation and generation: An fMRI study identifying common neural substrates between cognitive reappraisal and cognitively generated emotions. Cognitive, Affective, \& Behavioral Neuroscience, 14(3), 923-938.

[23] Gross JJ and Muñoz RF. (1995). Emotion regulation and mental health. Clinical psychology: Science and practice, 2(2), 151-164.

[24] Abbasi M, Pirani Z and Salehi E. (2017). Investigate the Relationship Between Positive and Negative Perfectionism With Emotional Well-being and Academic Engagement in Nurse's Students. Education Strategies in Medical Sciences, 10(6), 447-454.

[25] Calvete E, Orue I and Hankin BL. (2013). Early maladaptive schemas and social anxiety in adolescents: The mediating role of anxious automatic thoughts. Journal of Anxiety Disorders, 27(3), 278-288.

\section{How to cite this article}

Zeinab H, Ali NA, Gita S and Reza K. (2020). The effect of schema therapy on emotion regulation, happiness, and procrastination in health center employees. World Journal of Advanced Research and Reviews, 5(1), 43-49. 